\title{
MORPHOMETRIC INDICES IN AN ANNUAL FISH-THE REDTAIL NOTHO, NOTHOBRANCHIUS GUENTHERI (ACTINOPTERYGII: CYPRINODONTIFORMES: NOTHOBRANCHIIDAE): INFLUENCE OF AGE AND GENDER
}

\author{
Ravindra PAWAR ${ }^{1,2^{*}}$, Shicui ZHANG ${ }^{1}$, and Changshui LIU ${ }^{1}$ \\ ${ }^{1}$ Laboratory of Evolution and Development, Ocean University of China, Qingdao 266003, China \\ ${ }^{2}$ College of Fisheries, DBS Konkan Agricultural University, Ratnagiri 415629, India
}

Pawar R., Zhang S., Liu C. 2012. Morphometric indices in an annual fish-the redtail notho, Nothobranchius guentheri (Actinopterygii: Cyprinodontiformes: Nothobranchiidae): Influence of age and gender. Acta Ichthyol. Piscat. 42 (4): 291-296.

Background. Though fishes grow indeterminately, very little is known of the effects of age on the morphometric indices (length, weight, and condition) in fishes as it is often difficult to cover the entire lifespan of a species in laboratory or nature. The presently reported study was thus conducted to elucidate the effects of age (and sex) on the growth indices using the annual fish and a laboratory model of aging.

Materials and methods. Experimental fish - the redtail notho, Nothobranchius guentheri (Pfeffer, 1893), were obtained by hatching the diapause eggs of the same parental lineage and reared over their entire lifespan. Length-weight measurements were recorded from 3-12 months and various indices (length-weight relation, Fulton's condition factor, and relative condition factor) were computed and compared statistically.

Results. Mean lengths, weights, length-weight relations (LWRs), Fulton's condition factor $(K)$ and relative condition factor $\left(K_{n}\right)$ varied significantly leading to differential indices based on age and sex. Age influenced all indices positively, which is indicative of the indeterminate growth typical of fishes.

Conclusion. Age was not seen to suppress the growth indices in the annual fish, which is suggestive of a healthy and delayed senescence in the annual fish $N$. guentheri. Whether other short- and long-lived finfish follow the same pattern needs further investigation.

Keywords: Annual fish; aging, growth, morphometric indices, condition indices, indeterminate growth

\section{INTRODUCTION}

Given its correlation to a number of other life history parameters including reproduction and survival, growth remains one of the most widely studied life history traits of fishes (Martin 1949, Beverton and Holt 1957, Beverton 1992, Hotos and Katselis 2011). Length-weight relation (LWR), Fulton's condition factor $(K)$, and the relative condition factor $\left(K_{n}\right)$ are some of the most widely used morphometric indices to assess fish condition (Froese 2006). Differences in the parameters of LWRs and other condition indices represent spatial variations (Sparre and Venema 1998) and mirror the influence of abiotic factors and food availability on fish growth (Mommsen 1998).

In natural populations, it seldom is possible to delineate the influences of extrinsic (environmental) and intrinsic or genetic (age, sex) factors on fish growth. Besides, younger and older life history stages are ill represented in the commercial fish catches, which provide the bulk of samples from natural populations. Alternatively, laboratory studies offer a suitable alternative by offering sufficient control over the environmental variables and also by providing access to all life history stages. Nonetheless, laboratory growth experiments are not always an easy option (Magnussen 2007).

As an attempt to overcome the inherent problems associated with acquiring the age-related growth indices and with understanding the effects of age on such indices, an annual fish-the redtail notho, Nothobranchius guentheri (Pfeffer, 1893) was used as model for aging studies. Such species are known as annual fishes since their life cycle appears to be completed within a single year (Myers 1952). Thus, the redtail notho was chosen for the presently reported study for the following reasons:

- Being a laboratory model (Gerhard 2007), it gives a possibility to exercise control over the environmental variables and thus discern the effect of genetic variables (age and sex) on the growth indices;

- Having a median lifespan of 12 months (Markofsky and Perlmutter 1972) it gives a possibility to obtain information on the growth indices for all the life history stages in a relatively short period; and

\footnotetext{
${ }^{*}$ Correspondence: Dr. Ravindra Pawar, College of Fisheries (DBS Konkan Agricultural University), Ratnagiri 415629, India, phone: 91-827563 5577, fax: 91-2352-232987, e-mail: ravindra.fisheries@gmail.com.
} 
- Being a model for vertebrate aging studies (Genade et al. 2005), the redtail notho provides new insights on understanding the influence of intrinsic factors, especially of aging, on the growth dynamics in fishes as a whole by covering the entire lifespan effectively.

Male $N$. guentheri have been assessed for their crosssectional growth and body composition, age at sexual maturity in relation to longevity, and for growth differences in subgroups of varying longevities (Markofsky and Perlmutter 1972, 1973, Markofsky 1976). The presently reported study was thus conducted to elucidate the effects of age and sex on the growth dynamics of the annual fish $N$. guentheri and interpret them in the broader contexts of the evolution of aging and senescence. The study also assumes great relevance since condition indices covering the entire lifespan are lacking for the species with or without context to age and gender.

\section{MATERIAL AND METHODS}

Fish and husbandry. Laboratory-hatched embryos of $N$. guentheri were reared in 1-L beakers (at 15 embryos per L) for two months followed by rearing in 40-L glass aquaria (at one fish per $\mathrm{L}$ of water) till the end of the experiment. Larvae were fed freshly hatched artemia nauplii twice a day; live tubifex worms were fed ad libitum from the third month onward in two rations per day. Water parameters were maintained in strict accordance with the requirements for the species, which prefers soft waters with near neutral $\mathrm{pH}$. Mean water temperature and $\mathrm{pH}$ during the entire culture duration was maintained at $27 \pm 1{ }^{\circ} \mathrm{C}$ and $7.1 \pm 0.1$, respectively. Experimental protocols involving the use of live fish were in accordance with the Ocean University of China's guidelines.

Data collection. LWR estimates for $N$. guentheri were recorded separately for males and females for 3-12 month-old $N$. guentheri population obtained from the same parents. Prior to each sampling, fish were not fed for $24 \mathrm{~h}$ to ensure uniform condition and were anesthetized using MS 222 (Sigma, St. Louis, USA) at $120 \mathrm{mg} \cdot \mathrm{L}^{-1}$. Individual fish were measured for their total length (TL) $[\mathrm{cm}]$ to the nearest $0.1 \mathrm{~cm}$ and body weight (BW) [g] to the nearest $0.001 \mathrm{~g}$. Lengths were measured by placing the fish on a graph paper; weights were determined using an analytical balance. Fish were briefly placed on a soft moist cloth to remove excess body moisture before weighing them individually.

Data recording. Length-weight data were recorded separately under three categories based on sex namely, both or combined sexes $(\mathrm{B} ; n=92)$, males $(\mathrm{M} ; n=29)$, and females $(\mathrm{F} ; n=63)$. Since the average lifespan of $N$. guentheri stocks raised and maintained in the laboratory was $\sim 12$ months (Pawar, unpublished*), the length-weight data were further segregated into three periods of four months each namely 1,2 , and 3 representing the first, second and the third four-month intervals of lifespan respectively. This resulted in a total of 12 categories or subsets: (B, M, F); (B1, B2, B3); (M1, M2, M3) and (F1, F2, F3). The same nomenclature has been adopt- ed for all analyses and discussions in the presently reported study. However, in order to fulfil the requirements of ANOVA associated with the estimation of $b$-value of the LWRs, the length-weight data were segregated into two halves (1 and 2) spanning the first and second six months of the lifespan for each category instead of three four-monthly groups as mentioned earlier. Thus, $b$-values were derived for nine subsets in all (B, M, F); (B1, B2); (M1, M2) and (F1, F2).

Models used. Age- and sex-based length-weight data were analyzed using different models for obtainment of following growth indices. Parameters $a$ and $b$ were obtained by logarithmic transformation of the length-weight relation (Ricker 1975) bearing the form

$$
W=a L^{b}(1)
$$

where, $W=$ body weight $[\mathrm{g}], L=$ total length $[\mathrm{cm}]$, $a=$ constant, and $b=$ regression coefficient. Fulton's condition factor, $K$ (Fulton 1904) was estimated from the length-weight data using the equation

$$
K=100 W L^{-3}(2)
$$

where, $W=$ fish weight $[\mathrm{g}], L=$ total length $[\mathrm{cm}]$. Multiplying $W L^{-3}$ by 100 brings the value of $K$ to unity (Froese 2006). Relative condition factor, $K_{n}$ (Le Cren 1951) was estimated by the equation $K_{n}=W W_{E}^{-1}$, where $W_{E}=$ the length-specific expected mass predicted from the LWR. In the presently reported study, the common (and not the sub-set specific) LWR derived for the $N$. guentheri population as a whole was employed in deriving the length-specific expected mass $\left(W_{E}\right)$.

Statistical analyses. Ordinary least square regression of log-transformed weight on length was performed. Significance of the LWR regressions were assessed by analysis of variance (ANOVA) in testing the hypothesis $\mathrm{H}_{0}: \beta=0$ against $\mathrm{H}_{\mathrm{A}}: \beta \neq 0$ (Zar 1996). Student's $t$-test (Zar 1996) was used to:

- test whether $b$ were significantly different from 3 , the isometric growth $\left(\mathrm{H}_{0}: \beta=3\right.$ against $\left.\mathrm{H}_{\mathrm{A}}: \beta \neq 3 ; \alpha=0.05\right)$; - compare the slopes of the LWRs for differences between sexes and/or ages; and

- compare the mean lengths, weights, $K$ and $K_{n}$ between different sub-sets.

Shapiro-Wilk normality test was used to test the normality of distribution of $b(\alpha=0.05)$. Outliers for parameters $a$ and $b$ were detected by determining the $95 \%$ confidence limits (CL) for mean $a$ and $b$.

\section{RESULTS}

Distribution of length and weight in $N$. guentheri. The total length of $N$. guentheri ranged from 1.5 to $5.5 \mathrm{~cm}$; mean $=2.9 \mathrm{~cm}($ standard error of the mean $\mathrm{SE}=0.8)$ and the body weight from 0.044 to $2.036 \mathrm{~g}$; mean $=0.371 \mathrm{~g}$ $(\mathrm{SE}=0.314)$. Mean lengths, weights, and their ranges for the 12 subsets are given in Table 1.

Among the sexes, females (F) had the lowest-, combined sexes $(\mathrm{B})$ the intermediate-, and males $(\mathrm{M})$ the highest mean length-weight values thus following the pattern $(\mathrm{F}<\mathrm{B}<\mathrm{M})$. Within categories, the trend was for the younger groups (F1, B1, M1) to have lower mean length-weight values as 
compared to the median age group (F2, B2, M2), which had intermediate values, followed by the older subsets of the population (F3, B3, M3). Thus, the overall length-weight distribution trend for $N$. guentheri in the presently reported study could be summarized by the formula:

$(\mathrm{F} 1<\mathrm{F} 2<\mathrm{F} 3)<(\mathrm{B} 1<\mathrm{B} 2<\mathrm{B} 3)<(\mathrm{M} 1<\mathrm{M} 2<\mathrm{M} 3)$ (3)

In statistical terms, the observed trend for the distribution of length across age and gender was:

$(\mathrm{F} 1<<<\mathrm{F} 2<<<\mathrm{F} 3) \sim(\mathrm{B} 1<<<\mathrm{B} 2<<<\mathrm{B} 3)<(\mathrm{M} 1<<\mathrm{M} 2<\mathrm{M} 3)$ where, $(<)=P<0.05,(<<)=P<0.01,(<<<)=P=$ $<0.001$, and $(\sim)=P>0.05$.

Mean weights closely followed the distributional trends in length with but one difference. For length, F did not differ significantly from $\mathrm{B}(\mathrm{F} \sim \mathrm{B})$ whereas, in terms of weight $\mathrm{F}$ differed significantly from $\mathrm{B}(\mathrm{F}<\mathrm{B})$. Statistically, distribution of weight in $N$. guentheri followed the trend:

$(\mathrm{F} 1 \ll<\mathrm{F} 2<<\mathrm{F} 3)<(\mathrm{B} 1 \ll<\mathrm{B} 2 \ll<\mathrm{B} 3)<(\mathrm{M} 1 \ll<\mathrm{M} 2 \ll<\mathrm{M} 3)$

Formulae (4) and (5) are depicted graphically in Figs. $1 \mathrm{a}$ and $1 \mathrm{~b}$, respectively.

Length-weight relation. Regression parameters of LWR, namely $a$ and $b$ (and their $\mathrm{CL}_{95 \%}$ ), the coefficient of determination $\left(r^{2}\right)$, and associated growth patterns for $N$. guentheri subsets are given in Table 2 . All LWRs were highly significant $(P<0.001)$ with $r^{2}>0.90$ except for F1 where $r^{2}$ was 0.88 . The exponent $b$ was lowest for F1 (2.309) and highest for M2 (3.062) and had a mean value of $2.711(\mathrm{SE}=0.282)$. Shapiro-Wilk $W$-test did not reject the normality of distribution of $b(W=0.9181 ; P=0.829)$. No outliers were detected.

Distribution of $b$-values across the different categories followed the trend:

$(\mathrm{F} 1<<<\mathrm{F} 2 \sim \mathrm{F})<<(\mathrm{B} 1<<<\mathrm{B}<<<\mathrm{B} 2)<<(\mathrm{M} 1<<\mathrm{M} \sim \mathrm{M} 2)$

Formula (6) is depicted in Fig. 2.

Fulton's and relative condition factor. Fulton's $(K)$ and the relative condition factor $\left(K_{n}\right)$ were estimated for all subsets of $N$. guentheri (Table 3 ). $K$ values ranged from
0.70 to $1.62($ mean $=1.2109)$; and $K_{n}$ values from 0.61 to $1.44($ mean $=0.9844)$. Mean $K$ was about 1.23 times mean $K_{n}$. Both $K$ and $K_{n}$ were highly correlated $(r=0.89)$ and had significant difference between their means $(P<0.05)$.

Between the three major categories, $\mathrm{F}$ had the lowest, B the median, and $\mathrm{M}$ the highest $K$ and $K_{n}$ values. Overall, $K$ and $K_{n}$ distribution thus followed the pattern $(\mathrm{F}<\mathrm{B}<\mathrm{M})$. Within each category, the trend was for the younger groups (F1, B1, M1) to have lower mean $K$ and $K_{n}$ values; the median age groups (F2, B2, M2) to have intermediate values; and the older subsets (F3, B3, M3) to have the highest condition. In statistical terms, the distribution of $K$ and $K_{n}$ can be expressed respectively as follows:

$(\mathrm{F} 1 \sim \mathrm{F} 2 \sim \mathrm{F} 3) \sim(\mathrm{B} 1 \sim \mathrm{B} 2 \sim \mathrm{B} 3)<(\mathrm{M} 1 \sim \mathrm{M} 2<\mathrm{M} 3) \quad$ (7)

$(\mathrm{F} 1<<\mathrm{F} 2 \sim \mathrm{F} 3)<(\mathrm{B} 1<\mathrm{B} 2<<\mathrm{B} 3)<<(\mathrm{M} 1 \sim \mathrm{M} 2<\mathrm{M} 3) \quad(8)$

Formulae (7) and (8) are represented graphically in Fig. $3 \mathrm{a}$ and $3 \mathrm{~b}$ respectively.

\section{DISCUSSION}

In the presently reported study the length-weight data covered the young and old fish alike. Age- and sex- based subsets of $N$. guentheri were found to have differential LWRs; all LWRs conformed to most statistical standards and were highly significant $(P<0.001)$. Except for F1 and F2, remaining $b$-values were found to lie within the valid range of 2.5-3.5 as proposed by Carlander (1969), with values of $b<2.5$ and $>3.5$ often reflecting a narrow size range (Carlander 1977). Considering the overall small-sized stature of $N$. guentheri and particularly its females (F) and their sub-classes (F1 and F2) within the whole population, $b$-values $<2.5$ seem more to be an exception rather than an aberration in the proposed range. In addition, significant differences in the $b$-values between the subsets were evident from formula (6)

LWR parameters are known to be influenced by water quality or food availability via fish growth (Mommsen

Table 1

Age- and sex-wise distribution of length and weight in Nothobranchius guentheri

\begin{tabular}{|c|c|c|c|c|c|c|c|c|c|}
\hline \multirow{2}{*}{ Subset } & \multirow{2}{*}{$n$} & \multicolumn{4}{|c|}{ Length $[\mathrm{cm}]$} & \multicolumn{4}{|c|}{ Weight $[\mathrm{g}]$} \\
\hline & & Mean & SE & Min & Max & Mean & SE & Min & Max \\
\hline B & 92 & 2.9 & 0.8 & 1.5 & 5.5 & 0.371 & 0.314 & 0.043 & 2.036 \\
\hline M & 29 & 3.4 & 0.7 & 1.8 & 5.5 & 0.586 & 0.384 & 0.071 & 2.036 \\
\hline $\mathrm{F}$ & 63 & 2.7 & 0.7 & 1.5 & 4.3 & 0.272 & 0.215 & 0.043 & 0.983 \\
\hline B1 & 35 & 2.1 & 0.6 & 1.5 & 3.4 & 0.149 & 0.143 & 0.043 & 0.502 \\
\hline B2 & 35 & 2.9 & 0.6 & 1.8 & 4.0 & 0.334 & 0.206 & 0.072 & 0.815 \\
\hline B3 & 22 & 4.0 & 0.6 & 3.2 & 5.5 & 0.827 & 0.414 & 0.409 & 2.036 \\
\hline M1 & 10 & 2.6 & 0.6 & 1.8 & 3.4 & 0.256 & 0.163 & 0.071 & 0.502 \\
\hline M2 & 10 & 3.5 & 0.3 & 2.9 & 4.0 & 0.575 & 0.155 & 0.272 & 0.815 \\
\hline M3 & 9 & 4.2 & 0.7 & 3.7 & 5.5 & 1.149 & 0.531 & 0.628 & 2.036 \\
\hline $\mathrm{F} 1$ & 25 & 1.8 & 0.3 & 1.5 & 2.5 & 0.071 & 0.048 & 0.043 & 0.191 \\
\hline $\mathrm{F} 2$ & 25 & 2.7 & 0.5 & 1.8 & 3.6 & 0.245 & 0.140 & 0.072 & 0.636 \\
\hline F3 & 13 & 3.8 & 0.4 & 3.2 & 4.3 & 0.648 & 0.190 & 0.409 & 0.983 \\
\hline
\end{tabular}

$\mathrm{SE}=$ standard error of the mean; $\mathrm{F}=$ females, $\mathrm{B}=$ both sexes, $\mathrm{M}=$ males; Suffixes 1,2 , and 3 represent up to 4-, up to 8-, and up to 12 - month periods of age, respectively within each category. 
1998) or by spatial variation (Sparre and Venema 1998). Temperature and/or starvation influence the parameter $b$ so much that it is possible to produce different growth stanzas experimentally through marked temperature changes or by feed restrictions alone (Martin 1949). In the presently reported study, diurnal and inter-annual variations of abiotic- (temperature, $\mathrm{pH}$, dissolved oxygen) and biotic (food availability) components were effectively taken care of. Thus, the observed differences in the $b$ values and of the condition factors for $N$. guentheri could therefore be ascribed to the endogenous (genetic) influences in the form of age and
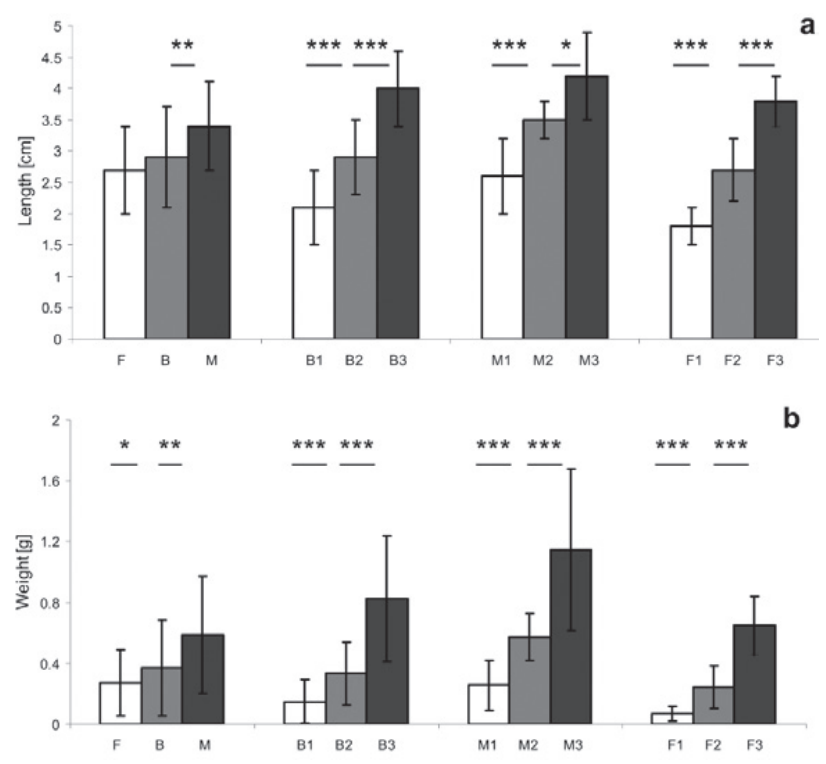

Fig. 1. Comparison of mean total lengths (a) and weights (b) of laboratory-hatched Nothobranchius guentheri by Student's $t$-test; $* P<0.05, * * P<0.01$, *** $P<$ $0.001 ; \mathrm{F}=$ females, $\mathrm{B}=$ both sexes, $\mathrm{M}=$ males; Suffixes 1, 2, and 3 represent up to 4-, up to 8-, and up to 12 - month periods of age, respectively within each category; values are mean \pm standard error of the mean sex on the growth. This is in accordance to the differential LWRs obtained for perch for different life stages, sexes, and stages of gonad development (Le Cren 1951). The existence of differential LWRs in $N$. guentheri validates these findings and justifies the need for examining and determining separate LWRs taking into account the sex and/or age (growth stanzas) of the population.

All the female- (F, F1, F2) and the common subsets $(\mathrm{B}, \mathrm{B} 1)$ displayed negative allometric growth $(b<3)$; all the male subsets (M, M1, M2) and B2 followed an isometric pattern $(b=3)$ (Table 2$)$. Thus, age had a conspicuous positive influence on the growth pattern of $N$. guentheri as the older half of the population (B2) showed highly significant $(P<0.001) b$-values than $\mathrm{B} 1$. The mean $b$ of nine LWRs representing different growth stanzas (ages and sizes) showed negatively allometric growth pattern $(b<3$; mean $b=2.711$ ) which, appropriately (Froese 2006) describes the growth type for $N$. guentheri as a whole.

Condition factors yield values close to unity and values $>1$ indicating better condition than an average indi-

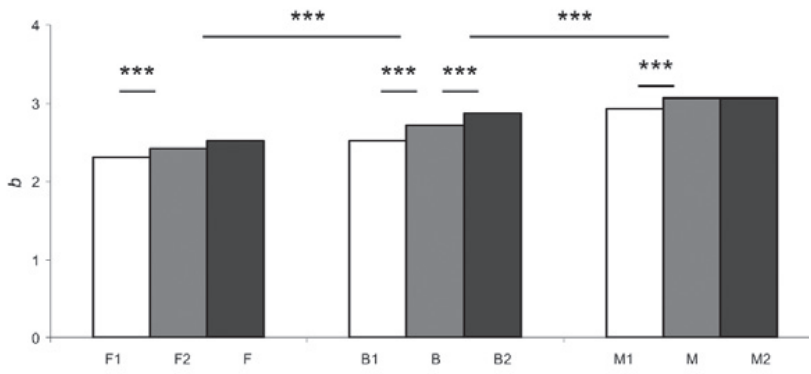

Fig. 2. Comparison of $b$-values of the length-weight relation of laboratory-hatched Nothobranchius guentheri, across the subsets, by Student's $t$-test, arranged in ascending order; $* * * P<0.001 ; \mathrm{F}=$ females, $\mathrm{B}=$ both sexes, $\mathrm{M}=$ males; Suffixes 1 and 2 represent up to 6- and more than six month-old age groups, respectively within each category

Table 2

Regression parameters of the differential length-weight relations for Nothobranchius guentheri across age and gender

\begin{tabular}{lcccccccc}
\hline \multirow{2}{*}{ Subset } & $n$ & \multicolumn{9}{c}{ Regression parameters } & \multirow{2}{*}{$\begin{array}{c}\text { Growth } \\
\text { pattern }\end{array}$} \\
\cline { 3 - 7 } & & $a$ & $b$ & $\mathrm{SE}(b)$ & $r^{2}$ & $a\left(\mathrm{CL}_{95 \%}\right)$ & $b\left(\mathrm{CL}_{95 \%}\right)$ & $\mathrm{N}$ \\
$\mathrm{B}$ & 92 & 0.0167 & 2.711 & 0.075 & 0.94 & $0.0143-0.0196$ & $2.562-2.860$ & $\mathrm{~N}$ \\
B1 & 66 & 0.0191 & 2.517 & 0.100 & 0.91 & $0.0158-0.0231$ & $2.317-2.717$ & $\mathrm{I}$ \\
$\mathrm{B} 2$ & 26 & 0.0150 & 2.870 & 0.197 & 0.90 & $0.0088-0.0256$ & $2.464-3.276$ & $\mathrm{I}$ \\
M & 29 & 0.0121 & 3.057 & 0.092 & 0.98 & $0.0096-0.0152$ & $2.869-3.245$ & $\mathrm{I}$ \\
M1 & 17 & 0.0135 & 2.929 & 0.112 & 0.98 & $0.0103-0.0176$ & $2.690-3.168$ & $\mathrm{I}$ \\
M2 & 12 & 0.0124 & 3.062 & 0.274 & 0.93 & $0.0054-0.0285$ & $2.451-3.672$ & $\mathrm{~N}$ \\
F & 63 & 0.0192 & 2.516 & 0.097 & 0.92 & $0.0159-0.0233$ & $2.322-2.711$ & $\mathrm{~N}$ \\
F1 & 49 & 0.0219 & 2.309 & 0.126 & 0.88 & $0.0176-0.0274$ & $2.055-2.563$ & $\mathrm{~N}$ \\
F2 & 14 & 0.0248 & 2.425 & 0.211 & 0.92 & $0.0138-0.0446$ & $1.966-2.885$ & $\mathrm{~N}$ \\
\hline
\end{tabular}

$\mathrm{SE}=$ standard error of the mean; $\mathrm{F}=$ females, $\mathrm{B}=$ both sexes, $\mathrm{M}=$ males; Suffixes 1,2 , and 3 represent up to 4-, up to 8-, and up to 12- month periods of age, respectively within each category; The growth pattern is based on $t$-test for $\mathrm{H}_{0}$ : $\beta=3$ against $\mathrm{H}_{\mathrm{A}}: \beta \neq 3 ; \mathrm{N}=$ negative allometric growth $(b \neq 3 ; P<0.05) ; \mathrm{I}=$ isometric growth $(b=3 ; P>0.05)$; CL: confidence limit. 
vidual with the same length and vice versa (Knaepkens et al. 2002). Based on the mean Fulton's condition factor $(K)$ value of $1.21, N$. guentheri population as a whole appeared to conform to good health condition. Besides, all subsets also possessed $K$ values $>1$. The mean relative condition $\left(K_{n}\right)$ value of 0.98 was marginally $<1(P>0.05)$. However, all the older subsets: B3, M3, and F3 had values $>1$ indicating an improvement in health status with age. For sexes combined, $K_{n}$ increased consistently with age (formula 8).

Fulton's condition factor, tended to overestimate condition since $K$ is based on the assumption of isometric growth ( $b=3$ ) whereas, the average $N$. guentheri population, in this study, exhibited negative allometric growth $(b<3)$. Relative condition factor $\left(K_{n}\right)$ thus seems more sensitive and appropriate in predicting the condition of the redtail notho as it better accounts for the deviations of an individual from the average weight for given length (Le Cren 1951) and is therefore recommended for exploring relative condition of individuals within a sample (Froese 2006).

The morphometric indices $\left(L, W, b, K, K_{n}\right)$ investigated in the presently reported study displayed conspicuous age- and gender- based trends. Age appeared to influence the indices positively. In particular, within a subset the older subsets (B3, M3, and F3) possessed higher indices for all the parameters tested as compared to the younger subsets. The findings indicate that aging does not retard growth or the health condition in the annual fish $N$. guentheri and thus validate the phenomenon of indeterminate growth as evidenced in most ectotherms. Secondly, gender or sex of the specimens also influenced all the morphometric indices greatly. Specifically, all the female subsets had the lowest values for all the indices as compared to their male counterparts with the combined subset (B) taking the median position. Thirdly, the Fulton's condition factor $(K)$ cannot provide a good estimate of the condition differences between the different growth stanzas since the growth pattern of the species investigated does not conform to the isometric type. Therefore, the relative condition factor appears to be a reliable index of assessing fish condition spanning all life history stages.

From an evolutionary perspective, the results ratify the phenomenon of delayed senescence arising out of indeterminate growth as common to fishes. Although the data presented herein covered the majority lifespan of $N$. guentheri, no signs, if any, of aging or senescence were evident from the obtained health indices at any stage for any age group for the combined population or the individual sexes. On the contrary, the condition indices improved with age, which is in complete agreement with Reznick et al. (2002) that the older age classes contribute greater to fitness in fishes and, according to Hamilton (1966) and Abrams (1993), such conditions favour and support delayed senescence.

In summarizing, the intrinsic factors - age and sexwere found to influence the growth indices pronouncedly in $N$. guentheri. The aging process proper did not seem to influence somatic growth in $N$. guentheri negatively since fish of the older age groups possessed better condition as compared to the younger groups. Sex-wise, the males displayed higher indices on all counts when compared to their female counterparts. Collectively, the results are indicative of negligible senescence (Keller and Murtha 2004)

Table 3

Distribution of mean Fulton's condition $(K)$ and relative condition factor $\left(K_{n}\right)$ in Nothobranchius guentheri in relation to age and gender

\begin{tabular}{lrcccc}
\hline \multirow{2}{*}{ Subset } & $n$ & \multicolumn{2}{c}{$K$} & \multicolumn{2}{c}{$K_{n}$} \\
\cline { 3 - 6 } & & Mean & SE & Mean & SE \\
\hline B & 92 & 1.21 & 0.15 & 0.98 & 0.16 \\
B1 & 29 & 1.21 & 0.09 & 0.89 & 0.12 \\
B2 & 63 & 1.20 & 0.15 & 0.98 & 0.15 \\
B3 & 35 & 1.26 & 0.22 & 1.12 & 0.20 \\
M & 35 & 1.30 & 0.15 & 1.10 & 0.16 \\
M1 & 22 & 1.26 & 0.08 & 0.99 & 0.09 \\
M2 & 10 & 1.27 & 0.14 & 1.09 & 0.12 \\
M3 & 10 & 1.45 & 0.20 & 1.31 & 0.16 \\
F & 9 & 1.17 & 0.13 & 0.92 & 0.13 \\
F1 & 25 & 1.16 & 0.08 & 0.82 & 0.07 \\
F2 & 25 & 1.18 & 0.14 & 0.93 & 0.13 \\
F3 & 13 & 1.16 & 0.15 & 1.01 & 0.12 \\
\hline SE
\end{tabular}

$\mathrm{SE}=$ standard error of the mean; $K=$ Fulton's condition factor, $K_{n}=$ relative condition factor, $\mathrm{F}=$ females, $\mathrm{B}=$ both sexes, $\mathrm{M}=$ males; Suffixes 1, 2, and 3 represent up to 4-, up to 8-, and up to 12 - month periods of age, respectively within each category.
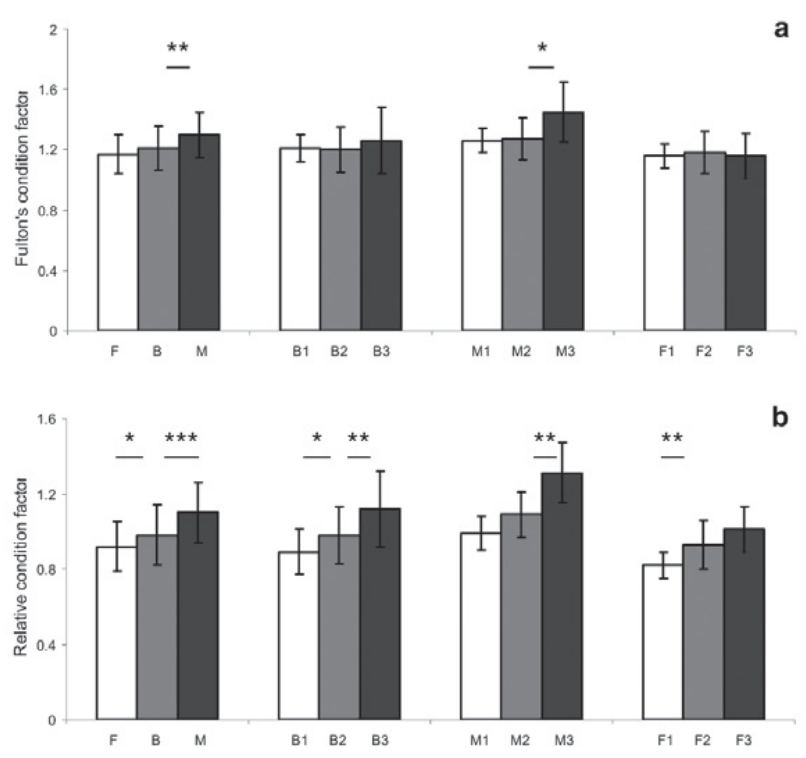

Fig. 3. Comparison of mean Fulton's condition factor, $K$ (a) and relative condition factor, $K_{n}$ (b) of laboratory-hatched Nothobranchius guentheri, by Student's $t$-test; $* P<0.05, * * P<0.01, * * * P<0.001$; $\mathrm{F}=$ females, $\mathrm{B}=$ both sexes, $\mathrm{M}=$ males; Suffixes 1,2 , and 3 represent up to 4-, up to 8-, and up to 12- month age groups, respectively within each category; values are mean \pm standard error of the mean 
in the annual fish $N$. guentheri in terms of the morphometric growth indices. Condition indices describing a majority of the lifespan of a finfish in the form of a statistical equation have been proposed for the first time.

\section{ACKNOWLEDGEMENTS}

This work formed a part of the doctoral dissertation of R.P., who was supported by a Chinese Government scholarship.

\section{REFERENCES}

Abrams P.A. 1993. Does increased mortality favor the evolution of more rapid senescence? Evolution 47: 877-887.

Beverton R.J.H. 1992. Patterns of reproductive strategy parameters in some marine teleost fishes. Journal of Fish Biology 41 (Suppl. sB): 137-160. DOI: $10.1111 / j .1095-8649.1992 . t b 03875 . x$

Beverton R.J.H., Holt S.J. 1957. On the dynamics of exploited fish populations. Chapman and Hall, London, UK. Facsimile reprint, 1993.

Carlander K.D. 1969. Handbook of freshwater fishery biology. Vol. 1. The Iowa State University Press, Ames, IA, USA.

Carlander K.D. 1977. Handbook of freshwater fishery biology. Vol.2. The Iowa State University Press, Ames, IA, USA.

Froese R. 2006. Cube law, condition factor and weight-length relationships: history, meta-analysis and recommendations. Journal of Applied Ichthyology 22 (4): 241-253. DOI: 10.1111/j.1439-0426.2006.00805.x

Fulton T.W. 1904. The rate of growth of fishes. 22nd Annual Report, Part III. Fisheries Board of Scotland, Edinburgh, Scotland.

Genade T., Benedetti M., Terzibasi E., Roncaglia P., Valenzano D.R., Cattaneo A., Cellerino A. 2005. Annual fishes of the genus Nothobranchius as a model system for aging research. Aging Cell 4 (5): 223-233.

DOI: $10.1111 / j .1474-9726.2005 .00165 . x$

Gerhard G.S. 2007. Small laboratory fish as models for aging research. Ageing Research Reviews 6 (1): 64-72. DOI: 10.1016/j.arr.2007.02.007

Hamilton W.D. 1966. The moulding of senescence by natural selection. Journal of Theoretical Biology 12 (1): 12-45. DOI: 10.1016/0022-5193(66)90184-6

Hotos G.N., Katselis G.N. 2011. Age and growth of the golden grey mullet Liza aurata (Actinopterygii: Mugiliformes: Mugilidae), in the Messolonghi-Etoliko Lagoon and the adjacent Gulf of Patraikos, Western Greece. Acta Ichthyologica et Piscatoria 41 (3): 147-157.

DOI: $10.3750 / A I P 2011.41 .3 .01$

Keller E.T., Murtha J.M. 2004. The use of mature zebrafish (Danio rerio) as a model for human aging and disease. Comparative Biochemistry and Physiology, Part C: Toxicology and Pharmacology 138 (3): 335-341. DOI: 10.1016/j.cca.2004.04.001

Knaepkens G., Knapen D., Bervoets L., Hänfling B., Verheyen E., Eens M. 2002. Genetic diversity and condition factor: a significant relationship in Flemish but not in German populations of the European bullhead (Cottus gobio L.). Heredity 89 (4): 280-287.

DOI: $10.1038 /$ sj.hdy. 6800133

Le Cren E.D. 1951. The length-weight relationship and seasonal cycle in gonad weight and condition in the perch (Perca fluviatilis). Journal of Animal Ecology 20 (?): 201-219.

Magnussen E. 2007. Interpopulation comparison of growth patterns of 14 fish species on Faroe Bank: Are all fishes on the bank fast-growing? Journal of Fish Biology 71 (2): 453-475. DOI: $10.1111 / \mathrm{j} .1095-8649.2007 .01502 . x$

Markofsky J. 1976. Longitudinal and cross-sectional observations of growth and body composition with age in laboratory populations of the male annual cyprinodont fish, Nothobranchius guentheri. Experimental Gerontology 11 (5-6): 171-177. DOI: $10.1016 / 0531-5565(76) 90030-9$

Markofsky J., Perlmutter A. 1972. Age at sexual maturity and its relationship to longevity in the male annual cyprinodont fish, Nothobranchius guentheri. Experimental Gerontology 7 (2): 131-135. DOI: $10.1016 / 0531-5565(72) 90007-1$

Markofsky J., Perlmutter A. 1973. Growth differences in subgroups of varying longevities in a laboratory population of the male annual cyprinodont fish, Nothobranchius guentheri (Peters). Experimental Gerontology 8 (2): 65-73.

DOI: $10.1016 / 0531-5565(73) 90016-8$

Martin W.R. 1949. The mechanics of environmental control of body form in fishes. Publications of the Ontario Fisheries Research Laboratory No. 70 (University of Toronto Studies, Biological Sciences No. 58) The University of Toronto Press, Toronto, Canada.

Mommsen T.P. 1998. Growth and metabolism. Pp. 65-97. In: Evans D.H. (ed.) The physiology of fishes. CRC Press, New York, NY, USA.

Myers G.S. 1952. Annual fishes. Aquarium Journal 23 (7): 125-141.

Reznick D., Ghalambor C., Nunney L. 2002. The evolution of senescence in fish. Mechanisms of Ageing and Development 123 (7): 773-789. DOI: 10.1016/S0047-6374(01)00423-7

Ricker W.E. 1975. Computation and interpretation of biological statistics of fish populations. Bulletin of the Fisheries Research Board of Canada 191: 1-382.

Sparre P., Venema S.C. 1998. Introduction to tropical fish stock assessment. Part 1. Manual. FAO Fisheries Technical Paper No. 306.1, Rev. 2. FAO, Rome.

Zar J.H. 1996. Biostatistical analysis. 3rd edn. Prentice-Hall, Englewood Cliffs, NJ, USA.

Received: 16 February 2012

Accepted: 4 October 2012

Published electronically: 31 December 2012 